STRUCTURAL BIOLOGY COMMUNICATIONS

ISSN 2053-230X

\section{Quo vadis, Acta Crystallographica F?}

\author{
Mark J. van Raaij*
}

Department of Molecular Structure, Centro Nacional de Biotecnologia, Consejo Superior de Investigaciones Cientificas, E-28049 Madrid, Spain. *Correspondence e-mail: mjvanraaij@cnb.csic.es

After a year and a half as Section Editor of Acta Crystallographica F, I thought it was high time to introduce myself and share some thoughts with you on the current situation and future directions of the journal. As a biochemist by training, I specialized in protein crystallography during my $\mathrm{PhD}$ and postdoc. Currently, I am a group leader at the Centro Nacional de Biotecnología in Madrid, Spain.

Acta Crystallographica $F$ is an online-only journal for the rapid publication of structural biology Research Communications, with the option of author-paid open access. We especially welcome new structural information, obtained by any technique, be it crystallography, electron microscopy, nuclear magnetic resonance spectroscopy or computational methods. We pride ourselves on exact standards of structure validation and reporting, standards which the IUCr journals in general have pioneered or adopted at an early stage.

We also publish Research Communications describing the successful crystallization of interesting macromolecules provided they include a new method, combination of methods, variant or 'trick' that may be applicable to other systems and thus useful for the general readership. We no longer publish routine Crystallization Communications because they do not attract sufficient interest.

Apart from Research Communications, we encourage the submission of Topical Reviews on subjects of interest to the structural biology community. For examples, see the recent general Topical Review on the complementarity of cryo-EM and X-ray crystallography (Vénien-Bryan et al., 2017), and the Topical Review on using NMR spectroscopy and X-ray crystallography in elucidating protein-glycan interactions (Blaum et al., 2018).

An option we are considering is the introduction of short technical notes, suggested by the former Acta Crystallographica F Editor Manfred Weiss. These would be short papers describing a technique useful to the structural biology community, without being a complete new method of doing something. Currently, many of 'tips and tricks of the trade' are only informally shared on bulletin boards, in workshops, during conference presentations or perhaps only by word of mouth in the laboratory. These technical notes have the potential to be well read, and will allow authors of other publications to cite a technique they have used without having to describe it in detail themselves.

While we are on the subject of citations, the Impact Factor is one of the measures by which a journal is judged, papers are often also judged by the Impact Factor of the journal they were published in, which is an incorrect use of this number (Moher et al., 2018). Although the Impact Factor is an incomplete measure of the journal's importance we cannot ignore it. The Impact Factor of Acta Crystallographica $F$ has roughly doubled in the past few years from 0.5 to almost 1 , and for the journal to become more attractive to potential authors, it is important to maintain and hopefully increase this, and other related measures, further. By focusing on the scientific quality of the published papers, this should be achievable.

Another important matter is establishing and maintaining a clear distinction between Acta Crystallographica $F$ and Acta Crystallographica D. We aim to publish shorter, perhaps more narrowly focused papers, and be faster than Acta Crystallographica D, not publish 'worse' or poorer quality work. Together with the Editor-in-Chief, the Editors of Acta Crystallographica $D$ and $F$ are working on making the difference clearer for readers and authors, and I will be writing more on this in the future.

Two main attractions we share with the other IUCr journals are the excellent copyediting services in Chester and the fact that we are scientific society journals. Unlike 
many other journals, net income from subscriptions and openaccess fees is ploughed back into science by subsidising meetings and attendees of these meetings, with a special focus on young scientists and scientists from comparatively underdeveloped countries. Surely these are important points which we should use to decide where to submit our papers and try to convince our colleagues to do the same!

\section{References}

Blaum, B. S., Neu, U., Peters, T. \& Stehle, T. (2018). Acta Cryst. F74, 451-462.

Moher, D., Naudet, F., Cristea, I. A., Miedema, F., Ioannidis, J. P. A. \& Goodman, S. N. (2018). PLoS Biol. 16, e2004089.

Vénien-Bryan, C., Li, Z., Vuillard, L. \& Boutin, J. A. (2017). Acta Cryst. F73, 174-183. 